\title{
PENYELESAIAN MASALAH TRAFFIC ASSIGNMENT DETERMINISTIK DAN APLIKASINYA DALAM PEMODELAN PERPARKIRAN
}

\author{
Aden \\ Program Studi Matematika FMIPA Universitas Pamulang \\ Email: dosen00527@unpam.ac.id
}

\begin{abstract}
Traffic Assignment is a problems to look for current pattern at route from vertex one to other vertex in an parking area having directive to seeking of optimum route. Deterministik is a method solving of problem related to programming linear, for the purpose in seeking of optimum route from vertex one to vertex the other writer analyses with method Algoritma Djikstra in manual and method Algoritma Djikstra by using programming at program Matlab which actually obtains the same end result as implementation from Traffic Assignment Deterministik. In seeking of optimum route at parking modelling hinges once to the parking vehicle capacities and assuring service. Particularly in traffic Assignment the traffic jam of vital importance its(the role in determining optimum route as well as queue model used in the route.
\end{abstract}

Keywords : programming linear, Algoritma Djikstra and Traffic Assignment Deterministik

\begin{abstract}
Abstrak
Traffic Assignment merupakan suatu permasalahan untuk mencari pola arus pada rute dari verteks satu ke verteks yang lainnya di suatu area perparkiran yang berpatokan terhadap pencarian rute optimum. Deterministik merupakan suatu metode penyelesaian masalah yang berkaitan dengan linier programming, untuk itu dalam pencarian rute optimum dari verteks satu ke verteks yang lainnya penulis menganalisa dengan metode Algoritma Djikstra secara manual dan metode Algoritma Djikstra dengan menggunakan pemrograman pada program Matlab yang ternyata memperoleh hasil akhir yang sama sebagai implementasi dari Traffic Assignment Deterministik. Dalam pencarian rute optimum pada pemodelan perparkiran bergantung sekali terhadap kapasitas kendaraan perparkiran tersebut dan pelayanan yang meyakinkan. Terlebih dalam traffic Assignment hal kemacetan sangat penting peranannya dalam menentukan rute optimum dan juga model antrian yang dipakai dalam rute tersebut.
\end{abstract}

Kata Kunci : linier programming, Algoritma Djikstra dan Traffic Assignment Deterministik.

\section{PENDAHULUAN}

Indonesia merupakan negara yang sangat besar dan mempunyai banyak pulau terlebih sering dikatakan sebagai negara dengan seribu pulau. Penduduk yang heterogen yang tersebar di wilayah Indonesia dengan berbagai suku, kebudayaaan, dan bahasa. Walaupun kenyataannya belum sepenuhnya pulau-pulau di Indonesia dihuni. Namun semangat untuk membangun bangsa terus saling bahu membahu. Dengan besarnya suatu negara, maka diperlukan planning yang sangat matang untuk menjalankan pemerintahan, baik dari segi bidang ekonomi, politik, kebudayaan, dan lain-lain.

Dalam bidang perekonomian, terutama masalah infrastruktur jalan memang harus sangat diperhatikan oleh pemerintah, karena sangat berpengaruh sekali terhadap distribusi hasil industri maupun pabrik-pabrik besar guna mengantarkan barang-barang pruduksinya ke daerah-daerah lain terutama untuk di ekspor ke luar negeri.

Salah satu penyebab masalah transportasi yang sering dijumpai di kota besar di Indonesia adalah terbatasnya ruas jalan yang dibutuhkan untuk mengalir arus lalu lintas. Permasalahan tersebut semakin diperparah oleh adanya kenyataan bahwa banyak ruas jalan yang beroperasi dengan kapasitas jauh lebih rendah dibandingkan dengan kapasitas yang seharusnya. Salah satu penyebabnya adalah kegiatan perparkiran di badan jalan. Penggunaan badan jalan sebagai lahan parkir merupakan salah satu sumber pendapatan daerah utama sehingga kebijakan perparkiran harus diarahkan selain untuk sedapat mungkin meningkatkan pendapatan asli daerah (PAD) juga harus memperhatikan keuntungan dan kerugian pengguna jalan (baik yang parkir maupun yang lewat di jalan tersebut). http://digilib.itb.ac.id/gdl.php?mod=browse7op=read\&id=jbptitbpp-gdl-grey-1999-hedihidaya- 
$\underline{1835 \& g=\text { Daerah }}$ Permasalahan trasfortasi tidak lagi hanya berkaitan dengan kurangnya infrastruktur jalan yang menghubungkan antar daerah, namun banyak hal yang menjadi permasalahan diantaranya dari segi biaya operasi kendaraan, kapasitas ruas jalan, laju atau kecepatan kendaraan, kemacetan, peraturan pemerintah yang mengatur tentang perparkiran atau adanya terminal bayangan, para pedagang yang berjualan di ruas jalan, dan masih banyak lagi permasalahan-permasalahan lainnya.

Masalah transportasi dan perparkiran harus secepatnya dicarikan solusinya oleh pemerintah pusat terlebih pemerintah daerah yang memang langsung berhadapan dengan masalah tersebut. Oleh karena itu, selain pemerintah mencari solusinya, masyarakatpun harus ikut andil juga untuk menyelesaikan masalah trasfortasi khususnya perparkiran agar secepatnya dapat diatasi dan menghasilkan kinerja yang baik. Apabila pemerintah dapat mencari solusinya, tetapi masyarakat tidak bersama-sama untuk mensukseskan program pemerintah, maka dapat menghambat program tersebut dan bahkan menjadi gagal.

Dengan timbulnya masalah transportasi ini, para pengusaha berusaha mencari solusi terutama bagaimana caranya agar dalam mendistribusikan produksinya dengan biaya termurah dan waktu yang sesingkat-singkatnya atau menggunakan rute yang optimum. Dimana dengan modal yang sekecilkecilnya dapat memperoleh keuntungan yang sebesar-besarnya.

Setelah mengetahui masalah tersebut di atas, penulis mencoba melakukan penelitian yang berkaitan dengan pemodelan perparkiran dengan metode penyelaisan masalah traffic assignment deterministik agar memperoleh pemodelan perparkiran yang maksimal dan memuaskan atau optimum.

Agar penelitian ini lebih terarah dan tidak meluas, maka pembahasan masalah dibatasi pada perparkiran. Dalam pembahasan masalah yang dibahas adalah mengenai arus, kecepatan mobil pada waktu arus bebas, waktu tempuh pada waktu arus bebas, waktu yang ditempuh yang diakibatkan ditentukannya batasan kapasitas pada rute dari verteks satu ke verteks yang lain, dan kapasitas kendaraan sebagai bahan penelitian dengan metode traffic assignment deterministik untuk mencari pemodelan perparkiran secara optimum. Setelah mengemukakan latar belakang masalah, identifikasi masalah, dan pembatasan masalah, maka peneliti merumuskan masalah, yaitu 1) Bagaimana mempelajari hubungan kecepatan-arus dan kurva ongkos arus, 2) Bagaimana mempelajari model pemilihan rute optimum secara analisis dan menggunakan program komputer Matlab yang terkait dengan masalah jalur rute dengan biaya termurah dan waktu tersingkat, 3) Bagaimana mempelajari Assignment perparkiran, 4) Bagaimana mengaplikasikan suatu model perparkiran dengan memperhatikan pertimbanganperimbangan praktis.

\section{METODE PENELITIAN}

Penelitian ini menggunakan metode kuantitatif. Metode ini sebagai metode ilmiah karena telah memenuhi kaidah-kaidan ilmiah yaitu konkrit (empiris), obyektif, terukur, rasional dan sistematis. Digunakan untuk meneliti pada populasi atau sampel tertentu, pengumpulan dan menggunakan instrument penelitian, analisis data bersifat statistic dengan tujuan untuk menguji hipotesis yang telah ditetapkan. Proses penelitian bersifat deduktif, dimana untuk menjawab rumusan masalah digunakan konsep atau teori sehingga dapat dirumuskan hipotesis.

Populasi (universe) adalah wilayah generalisasi yang terdiri dari atas objek atau subjek yang mempunyai kuantitas dan karakteristis tertentu yang ditetapkan oleh peneliti untuk dipelajari dan kemudian ditarik kesimpulan.

Jadi populasi bukan hanya orang, tetapi juga benda-benda alam yang lain. Populasi bukan sekedar jumlah yang ada pada objek atau subjek yang dipelajari, tetapi meliputi seluruh karakteristis atau sifat yang dimiliki oleh objek atau subjek itu. populasi yang diambil oleh penulis sebagai penelitian adalah traffic atau lalu lintas. Sampel adalah sebagaian dari jumlah dan karakteristik yang dimiliki oleh populasi tersebut. Teknik penentuan sampel peneliti menggunakan metode Pengambilan Sampel Wilayah (Area Sampling) dan dimana wilayah yang peneliti ambil sebagai sampel adalah wilayah perparkiran. Sampel yang di ambil adalah jumlah kendaraan yang masuk dan keluar dalam perparkiran, kecepatan kendaraan 
ketika masuk dan keluar dari area perparkiran, panjang rute, waktu yang diperlukan kendaraaan untuk parkir di tempat perparkiran.

Hipotesis dalam penelitian ini adalah :

Ho : Metode traffic assignment dapat diterapkan untuk menyelesaikan permasalahan pemodelan perparkiran.

Ha :Metode traffic assignment tidak dapat diterapkan untuk menyelesaikan permasalahan pemodelan perparkiran.

Teknik pengumpulan data yang digunakan untuk dianalisis, penulis menggunakan literatur dengan berbagai macam referensi yang berhubungan dengan tema yang diteliti. Selain itu, peneliti membuat simulasi data tentang masalah denah perparkiran, kecepatan kendaraan pada waktu arus bebas, waktu yang ditempuh dalam keadaan arus bebas, kapasitas kendaraan dalam rute, jumlah unit yang melalui rute dalam $1 \mathrm{jam}$, dan tingkat kemacetan dalam rute. Metode Analisis data yang digunakan dalam menentukan waktu yang ditempuh untuk melalui rute dari verteks satu ke verteks yang lainnya adalah menggunakan data dari data simulasi yang telah dibuat.

Pengolahan data dilakukan dengan cara dua metode yaitu dengan manual dan mengunakan program komputer matlab. Metode manual dibantu dengan menggunakan program komputer exel dengan cara memasukkan persamaan yang akan dicari kedalam program exel, supaya lebih valid dalam perhitungannya.

Adapun langkah-langkah dalam analisa, secara singkat dapat dijelaskan sebagai berikut :

1) Hitunglah nilai waktu yang ditempuh untuk melalui rute dari verteks satu ke verteks lainnya (t) dengan menggunakan persaman (2.33).

2) Waktu yang ditempuh untuk melalui rute dari verteks satu ke verteks lainnya (t) hasil perhitungan yang nantinya akan dipergunakan untuk mencari lintasan optimum relatif dari verteks satu ke verteks yang lainnya (1) dengan menggunakan persamaan (2.34).

3) Lintasan optimum yang telah dihitung, selanjutnya kita akan mencari jalur optimum dari area masuk perparkiran atau pada denah perparkiran pada baris ke-1 dan kolom ke-1 atau A menuju ke are keluar perparkiran atau pada denah perparkiran pada baris ke-11 dan kolom ke-11 atau B dengan menggunakan persamaan (2.30) dan persamaan (2.31).

4) Untuk pembanding jalur optimum yaitu dengan waktu tercepat dan biaya termurah, menggunakan program komputer yang dibuat oleh penulis, tetapi sebelum membuat program komputer terlebih dahulu membuat diagram alir analisis program komputer untuk Matlab.

5) Selanjutnya membandingkan hasil akhir antara metode manual dengan matlab.

6) Langkah terakhir membahas traffic assignment perparkiran.

\section{HASIL DAN PEMBAHASAN}

\subsection{Penyelesaian Permasalahan Algoritma Djikstra}

Langkah awal adalah:

Tentukan yang termasuk jalur optimum $\mathrm{S}=\{(1,1)\}$

Iterasi ke-1:

$\mathrm{O}(1,2)=1[(1,1) ;(1,2)]=2,27$

$\mathrm{O}(2,1)=1[(1,1) ;(2,1)]=1,97$

$\mathrm{O}(2,2)$ dan lain-lain $=\infty$

Nilai $\mathrm{O}(\mathrm{i}, \mathrm{j})$ yang terkecil adalah $\mathrm{J}(2,1)=1,97 \ni$ verteks $(2,1)$ menjadi anggota himpunan jalur optimum $\mathrm{S}$.

Jadi $\quad S=\{(1,1) ;(2,1)\}$.

Iterasi ke-2:

$\mathrm{O}(2,2)=\mathrm{O}(2,1)+1[(2,1) ;(2,2)]=1,97+1,47=3,44$ 
$\mathrm{O}(3,1)=\mathrm{O}(2,1)+1[(2,1) ;(3,1)]=1,97+2,80=4,77$

Nilai $\mathrm{O}(\mathrm{i}, \mathrm{j})$ yang terkecil adalah $\mathrm{O}(2,2)=3,44 \quad \exists$ verteks $(3,1)$ menjadi anggota himpunan jalur optimum $\mathrm{S}$.

Jadi $\mathrm{S}=\{(1,1) ;(2,1) ;(2,2)\}$.

Iterasi ke-3:

$\mathrm{O}(1,2)=\mathrm{O}(2,2)+1[(2,2) ;(1,2)]=3,44+1,91=5,35$

$\mathrm{O}(2,3)=\mathrm{O}(2,2)+1[(2,2) ;(2,3)]=3,44+0,45=3,89$

$\mathrm{O}(3,2)=\mathrm{O}(2,2)+1[(2,2) ;(3,2)]=3,44+2,65=6,09$

Nilai $\mathrm{O}(\mathrm{I}, \mathrm{j})$ yang terkecil adalah $\mathrm{O}(2,3)=3,89 \ni$ verteks $(2,3)$ menjadi anggota himpunan jalur optimum $\mathrm{S}$.

Jadi $\quad \mathrm{S}=\{(1,1) ;(2,1) ;(2,2) ;(2,3)\}$

Iterasi ke-4:

$\mathrm{O}(1,3)=\mathrm{O}(2,3)+1[(2,3) ;(1,3)]=3,89+0,57=4,46$

$\mathrm{O}(2,4)=\mathrm{O}(2,3)+1[(2,3) ;(2,4)]=3,89+0,51=4,40$

$\mathrm{O}(3,3)=\mathrm{O}(2,3)+1[(2,3) ;(3,3)]=3,89+2,21=6,10$

Nilai $\mathrm{O}(\mathrm{I}, \mathrm{j})$ yang terkecil adalah $\mathrm{O}(2,4)=4,40 \ni$ verteks $(2,4)$ menjadi anggota himpunan jalur optimum $\mathrm{S}$.

Jadi $\quad \mathrm{S}=\{(1,1) ;(2,1) ;(2,2) ;(2,3) ;(2,4)\}$

Iterasi ke-5:

$\mathrm{O}(1,4)=\mathrm{O}(2,4)+1[(2,4) ;(1,4)]=4,40+0,66=5,06$

$\mathrm{O}(2,5)=\mathrm{O}(2,4)+1[(2,4) ;(2,5)]=4,40+0,47=4,87$

$\mathrm{O}(3,4)=\mathrm{O}(2,4)+1[(2,4) ;(3,4)]=4,40+0,65=5,05$

Nilai $\mathrm{O}(\mathrm{i}, \mathrm{j})$ yang terkecil adalah $\mathrm{O}(2,5)=4,87 \ni$ verteks $(2,5)$ menjadi anggota himpunan jalur optimum S.

Jadi $\quad \mathrm{S}=\{(1,1) ;(2,1) ;(2,2) ;(2,3) ;(2,4) ;(2,5)\}$.

Iterasi ke-6:

$\mathrm{O}(1,5)=\mathrm{O}(2,5)+1[(2,5) ;(1,5)]=4,87+0,55=5,42$

$\mathrm{O}(2,6)=\mathrm{O}(2,5)+1[(2,5) ;(2,6)]=4,87+0,46=5,33$

$\mathrm{O}(3,5)=\mathrm{O}(2,5)+1[(2,5) ;(3,5)]=4,87+0,73=5,60$

Nilai $\mathrm{O}(\mathrm{i} . \mathrm{j})$ yang terkecil adalah $\mathrm{O}(2,6)=5,33 \ni$ verteks $(2,6)$ menjadi anggota himpunan jalur optimum $\mathrm{S}$.

Jadi $\quad \mathrm{S}=\{(1,1) ;(2,1) ;(2,2) ;(2,3) ;(2,4) ;(2,5) ;(2,6)\}$.

Iterasi ke-7:

$\mathrm{O}(1,6)=\mathrm{O}(2,6)+1[(2,6) ;(1,6)]=5,33+0,51=5,84$

$\mathrm{O}(2,7)=\mathrm{O}(2,6)+1[(2,6) ;(2,7)]=5,33+0,42=5,75$

$\mathrm{O}(3,6)=\mathrm{O}(2,6)+1[(2,6) ;(3,6)]=5,33+0,60=5,93$

Nilai $\mathrm{O}(\mathrm{I}, \mathrm{j})$ yang terkecil adalah $\mathrm{O}(2,7)=5,75 \ni$ verteks $(2,7)$ menjadi anggota himpunan jalur optimum S.

Jadi $\quad \mathrm{S}=\{(1,1) ;(2,1) ;(2,2) ;(2,3) ;(2,4) ;(2,5) ;(2,6) ;(2,7)\}$.

Iterasi ke-8:

$\mathrm{O}(1,7)=\mathrm{O}(2,7)+1[(2,7) ;(1,7)]=5,75+3,50=9,25$

$\mathrm{O}(2,8)=\mathrm{O}(2,7)+1[(2,7) ;(2,8)]=5,75+0,82=6,57$

$\mathrm{O}(3,7)=\mathrm{O}(2,7)+1[(2,7) ;(3,7)]=5,75+2,53=8,28$

Nilai $\mathrm{O}(\mathrm{i}, \mathrm{j})$ yang terkecil adalah $\mathrm{O}(2,8)=6,57 \ni$ verteks $(2,8)$ menjadi anggota himpunan jalur optimum $\mathrm{S}$.

Jadi $\quad \mathrm{S}=\{(1,1) ;(2,1) ;(2,2) ;(2,3) ;(2,4) ;(2,5) ;(2,6) ;(2,7) ;(2,8)\}$.

Iterasi ke-9: 
$\mathrm{O}(1,8)=\mathrm{O}(2,8)+1[(2,8) ;(1,8)]=6,57+2,36=8,93$

$\mathrm{O}(2,9)=\mathrm{O}(2,8)+1[(2,8) ;(2,9)]=6,57+2,96=9,53$

$\mathrm{O}(3,8)=\mathrm{O}(2,8)+1[(2,8) ;(3,8)]=6,57+3,04=9,61$

Nilai $\mathrm{O}(\mathrm{I}, \mathrm{j})$ yang terkecil adalah $\mathrm{O}(1,8)=8,93 \ni$ verteks $(1,8)$ mejadi anggota himpunan jalur optimum $\mathrm{S}$.

Jadi $\quad \mathrm{S}=\{(1,1) ;(2,1) ;(2,2) ;(2,3) ;(2,4) ;(2,5) ;(2,6) ;(2,7) ;(2,8) ;(1,8) ;\}$

Iterasi ke-10:

$\mathrm{O}(1,9)=\mathrm{O}(1,8)+1[(1,8) ;(1,9)]=8,93+0,54=9,47$

$\mathrm{O}(2,8)=\mathrm{O}(1,8)+1[(1,8) ;(2,8)]=8,93+\infty=\infty$, karena $1[(2,8) ;(1,8)]$ sudah dilewati, maka nilainya $\infty$.

Nilai $\mathrm{O}(\mathrm{I}, \mathrm{j})$ yang terkecil adalah $\mathrm{O}(1,9)=9,47 \ni$ verteks $(1,9)$ menjadi anggota himpunan jalur optimum $\mathrm{S}$.

Jadi $S=\{(1,1) ;(2,1) ;(2,2) ;(2,3) ;(2,4) ;(2,5) ;(2,6) ;(2,7) ;(2,8) ;(1,8) ;(1,9)\}$.

Iterasi ke-11:

$\mathrm{O}(1,10)=\mathrm{O}(1,9)+1[(1,9) ;(1,10)]=9,47+2,09=11,56$

$\mathrm{O}(2,9)=\mathrm{O}(1,9)+1[(1,9) ;(2,9)]=9,47+2,24=11,71$

Nilai $\mathrm{O}(\mathrm{I}, \mathrm{j})$ yang terkecil adalah $\mathrm{O}(1,10)=11,56 \ni$ verteks $(1,10)$ menjadi anggota himpunan jalur optimum $S$.

Jadi $\mathrm{S}=\{(1,1) ;(2,1) ;(2,2) ;(2,3) ;(2,4) ;(2,5) ;(2,6) ;(2,7) ;(2,8) ;(1,8) ;(1,9) ;(1,10)\}$. Iterasi ke-12:

$\mathrm{O}(1,11)=\mathrm{O}(1,10)+1[(1,10) ;(1,11)]=11,56+2,42=13,98$

$\mathrm{O}(2,10)=\mathrm{O}(1,10)+1[(1,10) ;(2,10)]=11,56+2,37=13,93$

Nilai $\mathrm{O}(\mathrm{I}, \mathrm{j} 0$ yang terkecil adalah $\mathrm{O}(2,10)=13,93 \ni$ verteks $(2,10)$ menjadi anggota himpunan jalur optimum $S$.

Jadi $\quad \mathrm{S}=\{(1,1) ;(2,1) ;(2,2) ;(2,3) ;(2,4) ;(2,5) ;(2,6) ;(2,7) ;(2,8) ;(1,8) ;(1,9) ;(1,10)$; $(2,10)\}$.

Iterasi ke-13:

$\mathrm{O}(2,11)=\mathrm{O}(2,10)+1[(2,10) ;(2,11)]=13,93+2,39=16,32$

$\mathrm{O}(1,10)=\mathrm{O}(2,10)+1[(2,10) ;(1,10)]=13,93+\infty=\infty$, karena $1[(2,10) ;(1,10)]$ sudah terlewati, maka nilainya $\infty$.

$\mathrm{O}(3,10)=\mathrm{O}(2,10)+1[(2,10) ;(3,10)]=13,93+0,56=14,49$

Nilai $\mathrm{O}(\mathrm{I}, \mathrm{j})$ yang terkecil adalah $\mathrm{O}(3,10)=14,49 \ni$ verteks $(3,10)$ menjadi anggota himpunan jalur optimum $S$.

Jadi $\quad \mathrm{S}=\{(1,1) ;(2,1) ;(2,2) ;(2,3) ;(2,4) ;(2,5) ;(2,6) ;(2,7) ;(2,8) ;(1,8) ;(1,9) ;(1,10)$; $(2,10) ;(3,10)\}$.

Iterasi ke-14:

$\mathrm{O}(3,11)=\mathrm{O}(3,10)+1[(3,10) ;(3,11)]=14,49+3,69=18,18$

$\mathrm{O}(2,10)=\mathrm{O}(3,10)+1[(3,10) ;(2,10)]=14,49+\infty=\infty$, karena $1[(3,10) ;(2,10)]$ sudah terlewati, maka nialainya $\infty$.

$\mathrm{O}(4,10)=\mathrm{O}(3,10)+1[(3,10) ;(4,10)]=14,49+0,61=15,00$

Nilai $\mathrm{O}(\mathrm{I}, \mathrm{j})$ yang terkecil adalah $\mathrm{O}(4,11)=15,00 \ni$ verteks $(4,10)$ menjadi anggota himpunan jalur optimum $\mathrm{S}$.

Jadi $\quad \mathrm{S}=\{(1,1) ;(2,1) ;(2,2) ;(2,3) ;(2,4) ;(2,5) ;(2,6) ;(2,7) ;(2,8) ;(1,8) ;(1,9) ;(1,10)$; $(2,10) ;(3,10) ;(4,10)\}$.

Iterasi ke-15:

$\mathrm{O}(4,11)=\mathrm{O}(4,10)+1[(4,10) ;(4,11)]=15,00+2,60=17,60$ 
$\mathrm{O}(3,10)=\mathrm{O}(4,10)+1[(4,10) ;(3,10)]=15,00+\infty=\infty$, karena $1[(4,10) ;(3,10)]$ sudah terlewati, maka nilainya $\infty$.

$\mathrm{O}(5,10)=\mathrm{O}(4,10)+1[(4,10) ;(5,10)]=15,00+1,79=16,79$

Nilai $\mathrm{O}(\mathrm{i}, \mathrm{j})$ yang terkecil adalah $\mathrm{O}(5,10)=16,79 \ni$ verteks $(5,10)$ menjadi anggota himpunan jalur optimum $S$.

Jadi $\quad \mathrm{S}=\{(1,1) ;(2,1) ;(2,2) ;(2,3) ;(2,4) ;(2,5) ;(2,6) ;(2,7) ;(2,8) ;(1,8) ;(1,9) ;(1,10)$; $(2,10) ;(3,10) ;(4,10) ;(5,10)\}$.

Iterasi ke-16:

$\mathrm{O}(5,11)=\mathrm{O}(5,10)+1[(5,10) ;(5,11)]=16,79+1,03=17,82$

$\mathrm{O}(4,10)=\mathrm{O}(5,10)+1[(5,10) ;(4,10)]=16,79+\infty=\infty$, karena $1[(5,10) ;(4,10)]$ sudah terlewati, maka nilainya $\infty$.

$\mathrm{O}(6,10)=\mathrm{O}(5,10)+1[(5,10) ;(6,10)]=16,79+0,82=17,61$

Nilai $\mathrm{O}(\mathrm{i}, \mathrm{j})$ yang terkecil adalah $\mathrm{O}(6,10)=17,61 \ni$ verteks $(6,10)$ menjadi anggota himpunan jalur optimum $S$.

Jadi $\mathrm{S}=\{(1,1) ;(2,1) ;(2,2) ;(2,3) ;(2,4) ;(2,5) ;(2,6) ;(2,7) ;(2,8) ;(1,8) ;(1,9) ;(1,10)$; $(2,10) ;(3,10) ;(4,10) ;(5,10) ;(6,10)\}$.

Iterasi ke-17:

$\mathrm{O}(6,11)=\mathrm{O}(6,10)+1[(6,10) ;(6,11)]=17,61+1,01=18,62$

$\mathrm{O}(5,10)=\mathrm{O}(6,10)+1[(6,10) ;(5,10)]=17,61+\infty=\infty$, karena $1[(6,10) ;(5,10)]$ sudah terlewati, maka nilainya $\infty$.

$\mathrm{O}(7,10)=\mathrm{O}(6,10)+1[(6,10) ;(7,10)]=17,61+0,54=18,15$

Nilai $\mathrm{O}(\mathrm{i}, \mathrm{j})$ yang terkecil adalah $\mathrm{O}(7,10)=18,15 \ni$ verteks $(7,10)$ menjadi anggota himpunan jalur optimum $S$.

Jadi $S=\{(1,1) ;(2,1) ;(2,2) ;(2,3) ;(2,4) ;(2,5) ;(2,6) ;(2,7) ;(2,8) ;(1,8) ;(1,9) ;(1,10)$; $(2,10) ;(3,10) ;(4,10) ;(5,10) ;(6,10) ;(7,10)\}$.

Iterasi ke-18:

$\mathrm{O}(7,11)=\mathrm{O}(7,10)+1[(7,10) ;(7,11)]=18,15+3,98=22,13$

$\mathrm{O}(6,10)=\mathrm{O}(7,10)+1[(7,10) ;(6,10)]=18,15+\infty=\infty$, karena $1[(7,10) ;(6,10)]$ sudah terlewati, maka nilainya $\infty$.

$\mathrm{O}(8,10)=\mathrm{O}(7,10)+1[(7,10) ;(8,10)]=18,15+0,66=18,71$

Nilai $\mathrm{O}(\mathrm{i}, \mathrm{j})$ yang terkecil adalah $\mathrm{O}(8,10)=18,71 \ni$ verteks $(8,10)$ menjadi anggota himpunan jalur optimum $S$.

Jadi $S=\{(1,1) ;(2,1) ;(2,2) ;(2,3) ;(2,4) ;(2,5) ;(2,6) ;(2,7) ;(2,8) ;(1,8) ;(1,9) ;(1,10)$; $(2,10) ;(3,10) ;(4,10) ;(5,10) ;(6,10) ;(7,10) ;(8,10)\}$.

Iterasi ke-19:

$\mathrm{O}(8,11)=\mathrm{O}(8,10)+1[(8,10) ;(8,11)]=18,71+0,93=19,64$

$\mathrm{O}(7,10)=\mathrm{O}(8,10)+1[(8,10) ;(7,10)]=18,71+\infty=\infty$, karena $1[(8,10) ;(7,10)]$ sudah terlewati, maka nilainya $\infty$.

$\mathrm{O}(9,10)=\mathrm{O}(8,10)+1[(8,10) ;(9,10)]=18,71+0,92=19,63$

Nilai $\mathrm{O}(\mathrm{i}, \mathrm{j})$ yang terkecil adalah $\mathrm{O}(9,10)=19,63 \quad \ni$ verteks $(9,10)$ menjadi anggota himpunan jalur optimum $S$.

Jadi $S=\{(1,1) ;(2,1) ;(2,2) ;(2,3) ;(2,4) ;(2,5) ;(2,6) ;(2,7) ;(2,8) ;(1,8) ;(1,9) ;(1,10)$; $(2,10) ;(3,10) ;(4,10) ;(5,10) ;(6,10) ;(7,10) ;(8,10) ;(9,10)\}$.

Iterasi ke-20:

$\mathrm{O}(9,11)=\mathrm{O}(9,10)+1[(9,10) ;(9,11)]=19,63+3,09=22,72$

$\mathrm{O}(8,10)=\mathrm{O}(9,10)+1[(9,10) ;(8,10)]=19,63+\infty=\infty$, karena $1[(9,10) ;(8,10)]$ sudah terlewati, maka nilainya $\infty$. 
$\mathrm{O}(10,10)=\mathrm{O}(9,10)+1[(9,10) ;(10,10)]=19,63+0,43=20,06$

Nilai $\mathrm{O}(\mathrm{i}, \mathrm{j})$ yang terkecil adalah $\mathrm{O}(10,10)=20,06 \ni$ verteks $(10,10)$ menjadi anggota himpunan jalur optimum $\mathrm{S}$.

Jadi $S=\{(1,1) ;(2,1) ;(2,2) ;(2,3) ;(2,4) ;(2,5) ;(2,6) ;(2,7) ;(2,8) ;(1,8) ;(1,9) ;(1,10)$; $(2,10) ;(3,10) ;(4,10) ;(5,10) ;(6,10) ;(7,10) ;(8,10) ;(9,10) ;(10,10)\}$.

Iterasi ke-21:

$\mathrm{O}(10,11)=\mathrm{O}(10,10)+1[(10,10) ;(10,11)]=20,06+2,11=22,27$

$\mathrm{O}(9,10)=\mathrm{O}(10,10)+1[(10,10) ;(9,10)]=20,06+\infty=\infty$, karena $1[(10,10) ;(9,10)]$ sudah terlewati, maka nilainya $\infty$.

$\mathrm{O}(11,10)=\mathrm{O}(10,10)+1[(10,10) ;(11,10)]=20,06+1,66=21,72$

Nilai $\mathrm{O}(\mathrm{i}, \mathrm{j})$ yang terkecil adalah $\mathrm{O}(11,10)=21,72 \ni$ verteks $(11,10)$ menjadi anggota himpunan jalur optimum $\mathrm{S}$.

Jadi $S=\{(1,1) ;(2,1) ;(2,2) ;(2,3) ;(2,4) ;(2,5) ;(2,6) ;(2,7) ;(2,8) ;(1,8) ;(1,9) ;(1,10)$; $(2,10) ;(3,10) ;(4,10) ;(5,10) ;(6,10) ;(7,10) ;(8,10) ;(9,10) ;(10,10) ;(11,10)\}$.

Iterasi ke-22:

$\mathrm{O}(11,11)=\mathrm{O}(11,10)+1[(11,10) ;(11,11)]=21,72+0,78=22,50$

$\mathrm{O}(10,10)=\mathrm{O}(11,10)+1[(11,10) ;(10,10)]=21,72+\infty=\infty$, karena $1[(11,10) ;(10,10)]$ sudah terlewati, maka nilainya $\infty$.

Jadi $\mathrm{S}=\{(1,1) ;(2,1) ;(2,2) ;(2,3) ;(2,4) ;(2,5) ;(2,6) ;(2,7) ;(2,8) ;(1,8) ;(1,9) ;(1,10)$; $(2,10) ;(3,10) ;(4,10) ;(5,10) ;(6,10) ;(7,10) ;(8,10) ;(9,10) ;(10,10) ;(11,10) ;(11,11)\}$

\subsection{Pembahasan}

\section{a. Perbandingan Analisa Jalur Optimum Algoritma Djikstra dengan Algoritma Djikstra pada Matlab.}

Analisia data untuk mencari jalur optimum pada denah perparkiran dengan menggunakan metode manual Algoritma Djikstra ternyata membutuhkan waktu yang cukup lama, ketelitian dan kejelian. Sedangkan mencari jalur optimum dengan menggunakan program komputer Matlab ternyata membutuhkan waktu yang lebih singkat dari pada menggunakan metode manual. Walaupun ada perbedaan dalam langkah aplikasinya, tetapi hasil akhir dari kedua metode tersebut sama yaitu mendapatkan jalur optimum yang ditempuh. Dimana jalur optimum yang ditempuh oleh kedua metode tersebut adalah :

$\mathrm{S}=\{(1,2) ;(2,1) ;(2,2) ;(2,3) ;(2,4) ;(2,5) ;(2,6) ;(2,8) ;(1,8) ;(1,9) ;(1,10) ;(2,10) ;$ $(3,10) ;(3,10) ;(4,10) ;(5,10) ;(6,10) ;(7,10) ;(8,10) ;(9,10) ;(10,10) ;(11,10) ;(11,11)\}$, yaitu $1 \mathrm{t}=22,50$.

\section{b. Assignment Perparkiran}

Layanan pada jaringan perparkiran hampir sama dengan jaringan pada transportasi umum. Seperti halnya ruas jalan, jaringan layanan perparkiran memuat bagian-bagian layanan baik bagi mobil maupun sepeda motor. Konsep kapasitas ruas dari verteks satu ke verteks yang lainnya dikaitkan dengan frekuensi kendaraaan yang melalui rute tersebut.

Jika seorang pengemudi kendaraan sedang melakukan perjalanan pada rute dari verteks satu ke verteks yang lain yang mengakibatkan terjadinya antrian, membuat jalan menjadi penuh, ini semua merupakan batasan kapasitas sampai pada tingkat yang maksimum.

Pemilihan rute pada perparkiran berkaitan erat dengan pengguna jasa perparkiran kendaraan. Ketika pengguna jasa perparkiran tersebut menuju ke sebuah perempatan rute, maka pengguna jasa perparkiran tersebut akan berhenti dan memilih rute yang sekiranya kemacetan yang terjadi pada jalur yang dipilih sangat kecil. Pada perempatan inilah diperlukan petunjuk bahwa rute yang akan dilalui pada verteks berikutnya akan mengalami suatu tingkat kemacetan yang tinggi atau rendah, supaya pengguna jasa perparkiran merasa nyaman dengan pelayanan 
perparkiran. Apalagi jika seorang pelanggan ketika akan keluar dari area perparkiran yang membutuhkan waktu yang lebih cepat, maka pelayanan petunjuk sangat diperlukan.

Jika para pengguna jasa perparkiran menghadapi masalah antrian, maka seorang pengguna jasa perparkiran tersebut akan terkena biaya yang diakibatkan dengan konsumsi bahan bakar yang proposional terhadap jarak rute dari verteks yang satu ke verteks yang lain. Untuk itu, ongkos pada rute tersebut bergantung juga pada panjang rute tersebut, dan kapasitas kendaraan yang berada pada rute tersebut mengalami tingkat kemacetan yang tinggi. Semakin tinggi tingkat kemacetan, maka biaya yang harus dikeluarkan akan semakin tinggi, dan sebaliknya semakin rendah tingkat kemacetan, maka akan semakin kecil ongkos yang harus dikeluarkan.

Teori antrian diciptakan dalam tahun 1909 oleh ahli matematika dan insinyur berkebangsaan Denmark yang bernama A.K. Erlang. Sistem antrian terlihat setiap hari, seperti deretan mobil yang berhenti karena traffic ligt, antrian dari permintaan telephone pada suatu switchboard, penonton pada gedung teater yang box office, pada restaurant menunggu pesanan, antrian pesawat - pesawat di lapangan udara, kendaraan yang mengantri pada perparkiran baik pada waktu masuk maupun keluar area perparkiran.

Pada subbab ini akan dibahas pemodelan antrian pada perparkiran yang mengakibatkan antri kendaraan baik pada waktu masuk atau keluar area perparkiran. Untuk itu, diperlukan penyelesaian masalah antrian dalam masalah perparkiran dengan menggunakan metode antrian untuk menentukan pemodelan yang optimum bagi perparkiran tersebut.

Tujuan dasar model-model antrian adalah untuk meminimumkan total dua biaya, yaitu biaya langsung penyediaan fasilitas pelayanan dan biaya tidak langsung yang timbul karena kendaraan yang akan masuk ke area perparkiran harus menunggu dan harus dilayani. Bila suatu sistem mempunyai fasilitas pelayanan lebih dari jumlah optimal, ini berarti membutuhkan investasi modal yang berlebihan, tetapi bila jumlahnya kurang dari optimal hasilnya adalah tertundanya pelayanan. model antrian yang akan dibahas adalah merupakan peralatan penting untuk sistem pengolahan yang menguntungkan dengan menghilangkan antrian. Elemen-elemen pokok dalam metode antrian adalah sebagai berikut:

(1.) Sumber Masukan (Input)

Sumber masukan dari suatu antrian dapat terdiri atas suatu populasi orang, barang, komponen atau kertas kerja yang dating pada system untuk dilayani. Barang yang dimaksud dalam antrian perparkiran adalah kendaraan baik mobil maupun sepeda motor.

(2.) Pola Kedatangan

Tingkat kedatangan suatu barang baik itu kendaraan maupun yang lainnya pada suatu area perparkiran sering mengikuti suatu distribusi probabilitas Poisson. Distribusi probabilitas Poisson adalah salah satu dari pola-pola kedatangan-kedatangan didistribusi secara random. Hal ini terjadi karena distribusi Poisson menggambarkan jumlah kedatangan per unit waktu bila sejumlah besar variabel-variabel random mempengaruhi tingkat kedatangan.

(3.) Disiplin Antrian

Disiplin antrian merupakan petunjuk pedoman keputusan yang digunakan untuk menyeleksi kendaraan yang memasuki antrian untuk dilayani terlebih dahulu (prioritas). Disiplin antrian yang paling umum adalah pedoman first come, first served (FCFS), yang pertama kali datang pertama kali dilayani.

(4.) Kepanjangan Antrian

Banyak sistem antrian dapat menampung jumlah kendaraan yang relatif besar, tetapi ada beberapa sistem yang mempunyai kapasitas yang terbatas. Jika kapasitas antrian menjadi faktor pembatas besarnya jumlah individu yang dapat dilayani dalam sistem secara 
nyata, berarti sistem mempunyai kepanjangan antrian yang terbatas (infinite), dan model antrian terbatas harus digunakan untuk menganalisa system tersebut.

(5.) Tingkat Pelayanan

Waktu yang digunakan untuk melayani kendaraan yang datang dalam suatu sistem disebut waktu pelayanan (service time) . Waktu ini mungkin konstan, tetapi juga sering acak (random). Bila waktu pelayanan mengikuti distribusi eksponensial atau distribusi acak, waktu pelayanan (yaitu unit/ jam) akan mengikuti suatu distribusi Poisson.

(6.) Keluar (Exit)

Sesudah seseorang atau barang telah selesai dilayani, maka akan keluar (exit) dari sistem antrian tersebut

Pengguanaan notasi Kendall's Notation untuk memecahkan model antrian merupakan alat yang efisien untuk mengidentifikasi. Berikut diberikan model umum :

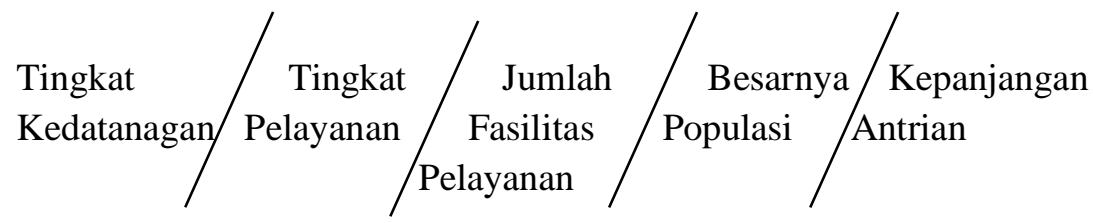

Model khusus di atas : M/ M/ 1/ I/ I.

Keterangan:

\begin{tabular}{|c|l|}
\hline Singkatan & Penjelasan \\
\hline M & Tingkatan kedatangan dan pelayanan Poisson. \\
\hline D & $\begin{array}{l}\text { Tingkat kedatangan atau pelayanan deterministik (diketahui } \\
\text { konstan). }\end{array}$ \\
\hline K & Distribusi Erlang waktu antar kedatangan atau pelayanan. \\
\hline S & Jumlah fasilitas pelayanan. \\
\hline I & Sumber populasi atau kepanjangan antrian terbatas (finite). \\
\hline
\end{tabular}

Dari pejelasan di atas, maka dipilihlah salah satu model yaitu:

\section{Model 1 : M/ M/ S/ I/ I.}

Populasi (I) Antrian (M)

(M/ I) Fasilitas pelayanan

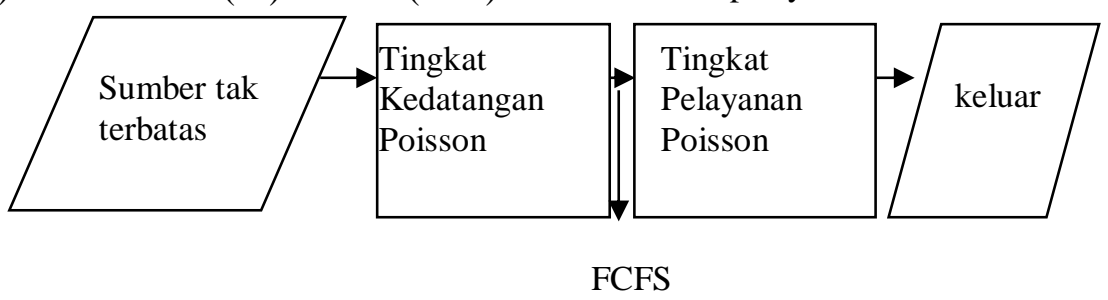

Kepanjangan antrian tak-terbatas (I)

Dengan model antrian seperti di atas, maka dapat dirumuskan permasalah-permasalah ke dalam bentuk persamaan-persamaan sebagai berikut :

$$
\begin{aligned}
\overline{n_{q}} & =\frac{\lambda^{2}}{\mu(\mu-\lambda)}, \ldots \ldots \ldots . . \\
\overline{t_{q}} & =\frac{\lambda}{\mu(\mu-\lambda)}, \ldots \ldots . . \\
\operatorname{Pn} & =\left(1-\frac{\lambda}{\mu}\right)\left(\frac{\lambda}{\mu}\right)^{n}, \\
\overline{n_{t}} & =\frac{\lambda}{\mu-\lambda}, \ldots \ldots \ldots . . \\
\overline{t_{t}} & =\frac{1}{\mu-\lambda}, \ldots \ldots \ldots . .
\end{aligned}
$$


$p=\frac{\lambda}{\mu}$

Keterangan:

$\lambda$ adalah tingkat kedatangan rata-rata (unit/ jam).

$\mu$ adalah tingkat pelayanan raa-rata (unit/jam).

$\sigma$ adalah deviasi standar tingkat pelayanan (unit/ jam).

$p$ adalah tingkat kegunaan bagian pelayanan (ratio).

$\mathrm{n}$ adalah jumlah unit dalam sistem pada suatu waktu (unit).

$\overline{n_{q}}$ adalah jumlah rata-rata dalam antrian (unit).

$\overline{n_{t}}$ adalah jumlah rata-rata dalam sistem ( init).

$\overline{t_{q}}$ adalah waktu rata-rata dalam antrian (jam).

$\overline{t_{t}}$ adalah waktu rata-rata dalam sistem total (jam).

$S$ adalah jumlah fasilitas pelayanan (unit pelayanan).

$Q$ adalah kepanjangan maksimum sitem (antrian plus ruang pelayanan) (unit).

$P_{n}$ adalah probabilitas jumlah $\mathrm{n}$ unit dalam sistem (frekuensi relatif).

$P_{o}$ adalah probabilitas tidak ada unit dalam sistem (frekuensi relatif).

$P_{w}$ adalah probabilitas menunggu dalam antrian.

$C_{s}$ adalah biaya pelayanan per satuan waktu per fasilitas pelayanan $(\mathrm{Rp} / \mathrm{jam} / \mathrm{server})$.

$C_{w}$ adalah biaya untuk menunggu per satuan waktu per individu (Rp/ jam/ unit).

$C_{t}$ adalah biaya total $=S C_{s}+\overline{n_{t}} C_{w} \quad,(\mathrm{Rp} / \mathrm{Jam})$.

Model perparkiran seperti di atas merupakan pemodelan yang apabila jumlah pelayanan yang berada di depan perparkiran lebih dari 2. Maka model perparkiran dengan menggunakan metode antrian dengan model $\mathrm{M} / \mathrm{M} / \mathrm{S} / \mathrm{I} / \mathrm{I}$, merupakan model yang sangat pas untuk perusahan yang bergerak di bidangnya.

c. Pertimbangan-Pertimbangan Praktis dalam Implementasi Model Perparkiran.

Submodel assignment memegang peranan yang sangat penting dalam tahap implementasi keseluruhan paket pemodelan perparkiran. Meskipun demikian, tidak ada prosedur pengujian standar untuk meyakinkan bahwa tingkatan assignment memberikan observasi-observasi sedekat mungkin. Kemungkinan calon untuk validasi eksternal suatu model adalah perhitungan perparkiran. Beberapa prosedur berikut dapat diterapkan pada semua jenis assignment, termasuk pada perparkiran

Prosedur ini dapat melacak sumber error dalam Traffic Assignment. Dalam pengkodean rute penulis menggunakan metode matrik, yaitu adanya baris dan kolom, sehingga untuk terjadi kesalahan sangat kecil.

Dalam memberikan jarak banyak error potensial, dikarenakan merupakan data simulasi yang penulis buat. Untuk itu dalam menentukan mana saja yang diperbolehkan untuk dilewati penulis menentukan seperti pada gambar (2.9), dan apabila jalur yang sudah terlewati maka tidak boleh dilalui kembali.

Bobot fungsi generalisasi ongkos di-assign menjadi waktu, jarak, dan fariabel yang lain termasuk di dalamnya (status rute jalan perparkiran dan lain-lain). Bentuk chi-square berikut dapat digunakan sebagai kriteria penyesuaian :

$\sum_{a} \frac{\left(V_{o_{a}}-V_{m_{a}}\right)^{2}}{V_{0_{a}}}$

Dengan:

$V_{\text {oa }}$ adalah arus hasil observasi pada ruas jalan $\alpha$.

$V_{m a}$ adalah ruas hasil pemodelan pada rute jalan $\alpha$ (arus diinterpretasikan dari $V_{s}$ ) 
Semakin kecilnilai formula di atas, maka semakin sesuai fungsi ongkos umum tersebut. Formula ini diaplikasikan pada sejumlah ruas perparkiran yang menjadi bagian suatu jaringan yang dianggap paling kritis, misalnya pada verteks-verteks. Nilai yang dihasilkan menurut formula (4.11). untuk keseluruhan jaringan akan menghasilkan suatu indikasi kesesuaian yang sifatnya menyeluiruh pula.

Awal yang baik adalah pengasumsian bahwa waktu mendasari pemilihan rute. Kemudian akan dioperasikan sebuah assignment secara lengkap dan dilakukan perhitungan formula (4.11). Selanjutnya akan diberikan penambahan bobot awal terhadap jarak (terhadap faktor yang lain ) dan dilakukan perhitungan ulang formula (4.11), sehingga dapat dibuat pemilihan parameter yang menghasilkan kesesuaian terbaik.

Pada kasus assignment perparkiran bobot relatif dari waktu pada waktu ruas bebas dan pada waktu di-assign kemacetan.

\section{d. Penyetelan yang Baik Sebuah Model Assigment}

Prosedur ini melibatkan pencarian parameter penyebaran untuk model-model assignment stokastik. harus diakui bahwa tidak ada model assignment yang akan menghasilakn observasiobservasi secara tepat. Pasti akan selalu terdapat variabilitas dalam jumlah perparkiran itu sendiri, error dalam matrik dalam rute pada verteks satu ke verteks yang lain yang digunakan dan dalam proporsi perilaku pemilihan rute yang sebenarnya yang akan menyisakan hal-hal yang tidak dapat dijelaskan. Hal-hal yang dipermasalahkan adalah bahwa waktu dalam keadaan bebas arus pada rute tersebut dan tingkat kemacetan atau antrian yang berada di area perparkiran harus seakurat mungkin dan model pencarian rute optimum dengan menggunakan Program Matlab harus diuji coba kembali.

\section{KESIMPULAN DAN SARAN}

Masalah traffic assignment merupkan salah satu aplikasi dari penyelesaian masalah perparkiran yang kian hari terus bertambah jumlah kendaraan yang pada akhirnya ikut bertambahnya perusahaan bidang jasa yang bergerak dalam bidang perparkiran. Dalam metode traffic assignment dalam perparkiran bertujuan untuk memperoleh hasil yang optimum dimana dengan menggunakan cara Algoritma Djikstra maupun pemodelan penyelesaian mencari jalur optimum dengan cara program komputer yang telah dibuat oleh penulis. Dimana hasil yang optimum ini merupakan waktu yang tecepat, biaya termurah dan menghindari kemacetan untuk menghasilkan rute dari verteks-verteks dari yang satu ke verteks yang lain, sehingga pengguna jasa perparkiran merasa nyaman dalam pelayanan dan diharapkan dapat kembali untuk parkir pada area perparkiran .

Pemilihan rute optimum yang mendasari metode traffic assignment ini diselesaikan dengan dua buah algoritma, yaitu Algoritma Djikstra dengan metode manual dan Algoritma Djikstra dengan menggunakan program komputer yang dibuat oleh penulis. Algoritma Djikstra dengan pemrograman Matlab memiliki kelebihan, karena dapat mencari beberapa verteks yang banyak dan mempunyai ketelitian yang lebih detail.

Traffic assignment selalu berpatokan pada masalah pemilihan rute optimum. Secara umum dapat dikatakan bahwa assignment perparkiran memiliki tingkat kesulitan yang hampir sama dengan dibandingkan dengan traffic assignment pada transportasi.

Tingkat kerumitan pada assignment perparkiran karena dsebabkan beberapa faktor diantaranya:

1) Layanan yang berada ketika akan masuk ke area perparkiran dan keluar area perparkiran,

2) waktu ketika akan keluar dari area perparkiran yang lambat diakibatkan karena adanya kapasitas arus atau adanya antrian, 
3) variabel tarif yang dikenakan oleh perparkiran dalam tiap jamnya, dan

4) batasan kapasitas pada rute dari verteks satu ke verteks yang lain sangat terbatas.

Karya ilmiah ini hanya mengangkat topik aplikasi riset tentang perparkiran , karena referensi tentang operasi riset sangat sedikit dan tentang traffic assignment pun masih jarang ada di Indonesia, sehingga penulis kesulitan dalam mencari referensinya. Oleh karena itu, penulis sangat berharap dikemudian hari banyak para ilmuwan matematika Indonesia untuk membuat buku tentang traffic Assignment dan kalaupun tidak bisa saran peneliti untuk menterjemahkan buku traffic assignment dari bahasa asing ke bahasa Indonesia.

Karya ilmiah ini atau skripsi ini yang berkaitan dengan aplikasi matematika di bidang perparkiran sangat jarang sekali, padahal semakin hari semakin bertambah perusahaan yang bergerak dibidangnya yang memerlukan referensi-referensi sebagai perbandingan guna mendapatkan keuntungan yang sebesar-besarnya. Untuk itu saran penulis adalah untuk dikembangkan kembali penelitian ini dengan cara peneliti langsung meneliti ke tempat perparkiran yang memang sudah ada sebagai aplikasi traffic assignment perparkiran yang nyata.

\section{DAFTAR PUSTAKA}

Arhani, Muhammad dan Anita Desiani, “Pemrograman Matlab”, Andi, Yogyakarta, 2005.

Dewi, Ema Roslina, "Skripsi penyelesaian Masalah Traffic Assignment Deterministik dan aplikasinya terhadap Transportasi", departemen pendidikan Nasional Universitas Gadjah Mada Fakultas Matematika dan Ilmu Pengetahuan Alam, Yogyakarta, 2004.

J. Purcell, Edwin dan Dale Verberg, "Kalkulus dan Geometri Analitis”, Erlangga, Jakarta, 1987.

Leithold, Louis, "Kalkulus dan Ilmu Analitik”, Erlangga, Jakarta, 1988.

Pangestu Subagyo, Marwan Asri, dan T. Hani Handoko, “ Dasar-Dasar Operation Research”, BPFE-Yogyakarta, Yogyakarta, 1990.

Sugiyono,"Statistik untuk Penelitian", CV Alfabeta, Bandung, 2006.

Suryadi."Seri Diktat Kuliah Pengantar Aljabar linier dan Geometri Analitik", Gunadarma, Jakarta, 1995.

Suryadi, “Seri Diktat Kuliah Pengantar Analisis Algoritma”“ Gunadarma, Jakarta, 1992.

Suryadi, "Pengantar Teori dan Algoritma Graph", Gunadarma, Jakarta, 1990.

Sutedjo, Budi dan Michael AN, “ Algoritma dan Teknik Pemrograman”,Adi Yogyakarta, Yogyakarta, 1997. 